\title{
Applying paleomagnetic oriented coring in investigating the lithofacies heterogeneity of terrigenous sediments
}

\author{
Lyubov Krasnoshchekova ${ }^{1, *}$, Daria Cherdantseva $^{2}$, and Maria Yurkova $^{1}$ \\ ${ }^{1}$ TPU, INR, Department of Geology and Mineral Exploration, 634050, Tomsk, Lenin Avenue, 30, Russia \\ ${ }^{2}$ TPU, INR, Department of Oil and Gas Industrial Facilities Design Construct, 634050, Tomsk, Lenin Avenue, 30, Russia
}

\begin{abstract}
This paper described the investigation of heterogeneous structure of oil field reservoirs via paleomagnetic oriented coring. As a rule, this heterogeneity develops during either sedimentation or secondary generation of terrigenous matter, which, in its turn, affects the lateral permeability in the layers. Applying oriented coring determines the vector behavior of anisotropic structure of oil fields which influence further production
\end{abstract}

\section{Introduction}

The heterogeneous reservoir structures in oil fields has been discussed in numerous geological research papers [1-4]. The concept that geological bodies have parallel-layered structures has been substituted by the fact that these bodies involve a more complex structure. These geological bodies are sediments of different facies that form the channels housing the further filtration of formation fluids.

The research target was the oil field located in S-E Western Siberia province within Tomsk Oblast. The investigated oil-bearing layer within this oil field was $\mathrm{U}_{1}^{2}$ in Vasugan suite traced in all correlative well logs. The formation of layer sediments occurred within coastal-marine conditions. The upper and lower contacts are limited by extensive and stable interlayered coal thicknesses which can be revealed on gamma-neutron and induction (electromagnetic) logging. In this case it is possible to conduct reflection picking of investigated hydrocarbon reservoirs. Layer sediment thickness is up to $10-15 \mathrm{~m}$ composed of aleurolites (siltstones) and sandstones which is intersected by carbonated interlayers $(0.5-1.0$ $\mathrm{m})$ grading laterally to argillaceous varieties. In singled-out field areas the upper sand bodies of $\mathrm{U}_{1}{ }^{2}$ could be replaced by clay matter often with glauconite. Glauconite presence on the boundary layers confirms the sediment genesis. Detailed study of glauconite features in the sedimentary rocks in this region is given in [5].

Currently, a sharply increasing layer water cutting has been observed within this oil field which indicates the existence of litho-petrophysical heterogeneity in the reservoirs. The present paper describes the investigation results of the lithofacies zonation of the layers via paleomagnetic oriented coring.

\section{Research methods}

Paleomagnetic orientation of rock samples was conducted in several stages. The diagram of oriented coring is depicted in fig.1. Algorithm analysis of the specific features of oriented rocks and thin sections, including their structural, lithological and petrophysical features, are presented in fig. 2 and in [6,7]. Methods investigating the morphological and micro structural characteristics of rocks are described in details in [8].

\section{Results and discussion}

According to petrophysical data, the predominate N-E direction of investigated magnetic rock properties and subnormally N-W orientation of elastic sandstone behavior was determined. Dominating development of elongated quartz grains was observed in N-E and N-W directions. Based on stated orientations, not only the microstructure patterns of optical axes of quartz individuals, but also the orientation of cracks and void space in thin sections were correlated.

\footnotetext{
* Corresponding author: krasnl@yandex.ru
} 


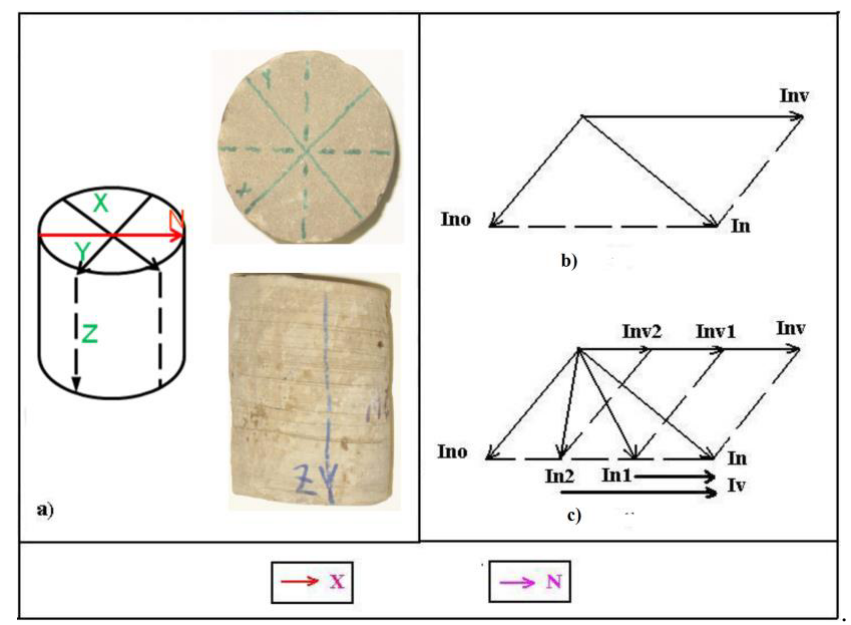

Fig. 1. Diagram of spatial oriented coring via paleomagnetic method: a) core sample with arbitrary coordinates (X, Y, Z) and calculated magnetic meridian plane (to viscous magnetization $-\mathrm{N}$ ); b) vector components of natural remanent magnetization (NRM): In - primary remanent magnetism Ino; viscous remanent magnetization - Inv; c) diagram of step-by-step demagnetization of natural remanent magnetization (In-In1-In2) with successive destruction of viscous magnetization (Inv-Inv1-Inv2) and separation of differential viscous element (Inv).

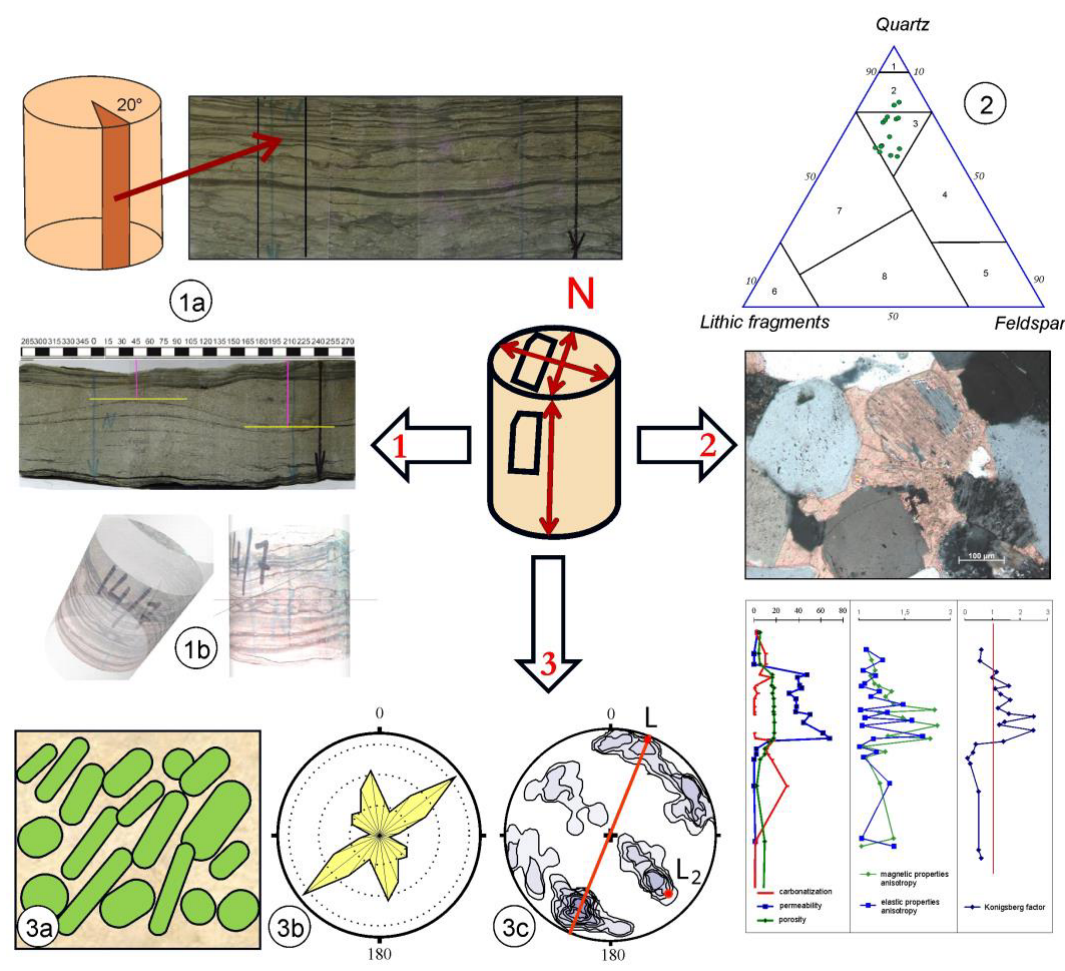

Fig. 2. Diagram of investigated oriented cores and thin sections: 1a - 3-D scanning (photo-scan) $1 b-3 D$ core imaging; 2 - lithological and petrophysical investigations; 3 - morphological and micro structural analysis: $3 \mathrm{a}$ - morphology and grain packing, $3 \mathrm{~b}$ - diagram of quartz grain elongation, $3 \mathrm{c}$ - diagram of optical quartz axes emergence 
Investigating quartz grain fracturing in rock thin sections showed random distribution of crack occurrence frequency in the cross-section. Development of cataclasis cracks, pores and channels, where fluids pass through, indicate the previously defined N-E and N-W orientation of magnetic parameters and elongated mineral skeleton grains. In mutually perpendicular thin sections of one sample, one can observe intensive fracturing anisotropy, sometimes up to 2-5 times. Rigid quartz grain skeleton deforms or cracks during stadial and/or epigenetic alterations, which, in its turn, increase, rock permeability.

To determine the facies conditions and formation mechanisms of sedimentary rock layers in investigated wells $50 \mathrm{~m}$ coring was plotted and described. The structure features of investigated sandstones and aleurolites (siltstones) were specified as photo scans according to oriented cores. The plotting method of panoramic core view is illustrated in fig. 3 .

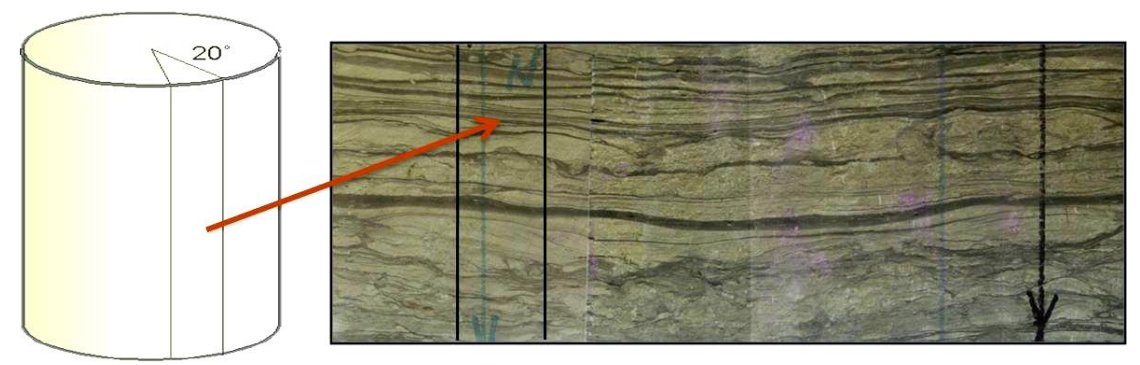

Fig. 3. Example of plotting panoramic core view

Plotting panoramic view of a core sample correlated with well depth makes it possible to determine the structure not by the flat rock cross-section, but by tracing the characteristic alterations in bulk. In this case, the orientation and layer dip angle, their quantitative relation, distribution pattern and interrelations are also determined. Panoramic coring is spaced so that northerly oriented samples coincide with zero degree. All studied rock reservoir structure features in combination with sediment grain-size analysis furthers the reconstruction and identification of sedimentogenesis facies. Besides above-mentioned method modeling 3D imaging of oriented coring in graphic editor Adobe PhotoShop CS 5 was applied.

Investigating the core was based on a sophisticated tool- plotting 3D transparently structured sample model. Input data included dimensional core features with constant diameter $(9.8 \mathrm{~cm})$, which is conditioned by the application of conventional drilling tools. The processing chain was divided into several sub-tasks: 1) designing graphic view of rock core sample; 2) plotting 3D model as a $9.8 \mathrm{~cm}$ cylinder surface which would be the further computer prototype.

The modeling itself involved a rather non-standard approach. The software product in investigating the model was the most common graphic editor Adobe Photoshop (version CS5 and higher) [9]. Preliminary investigation of the core surface involved designing standard 3D object based on a primitive cylinder with the diameter corresponding to the diameter of the circular image of the original sample. Property alterations of this object resulted in semi-transparent dimensional sample. Core model was rotated within the range of 0-3600 in all three coordinating plane axes. The angles were measured by adding two straight angles and reflecting angle value (fig. 4). The following illustration shows an example of measuring layer incident angle of 13.40 .

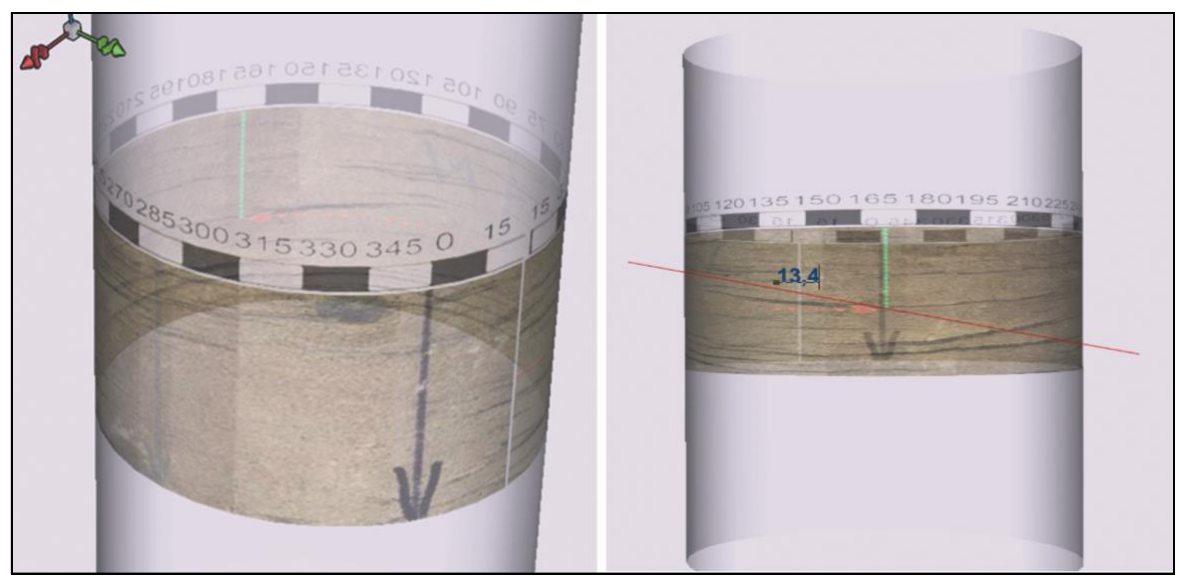

Fig. 4. 3D visual oriented core and layer incident angle measurement in graphic editor Adobe Photoshop CS 5 


\section{Conclusion}

Applying paleomagnetic oriented coring opens up new opportunities in reconstructing and identifying the facies conditions of sedimentation in oil-bearing fields. Furthermore, oriented samples make it possible to investigate the specific features of reservoirs in details, taking into consideration all heterogeneous layers and as a result, plot real-time models of different oil fields.

\section{References}

1. N. J.C Farrell., D. Healy , C. Taylor, Journal of Structural Geology, 63 50-67 (2014)

2. D. Healy et al, Geological Society special publication, 367 247-253 (2012)

3. L. Louis, T.-M. N. Chen, C. David, P. Robion, T.-f. Wong and S.-R. Song, Journal of Structural Geology, 30 948-962 (2008)

4. V. Merkulov, D. Aleksandrov, L. Krasnoshchekova et al, UKOS Scientific Vestnik, 10 3336 (2004)

5. M.A. Rudmin, I.V. Reva, A.P. Gunko, A.K. Mazurov, R.N. Abramova. IOP Conf. Ser. Earth Environ. Sci. 27. 012026 (2015)

6. M. Korovin and V Merkulov, Petroleum Engineering, 1 24-30 (2015)

7. V. Merkulov, L. Krasnoshchekova, Gazovaya promyishlennost, 3/703 22-27 (2014)

8. D. Cherdantseva and L Krasnoshchekova. IOP Conf. Ser. Earth Environ. Sci. 21012007 (2014)

9. L.A Krasnoschekova, V.P Merkulov, D.A. Cherdantseva, I.V. Ryashentsev. Geomodel 2015 17th Scientific-Practical Conference on Oil and Gas Geological Exploration and Development, Pages 255-259 (2015) 